\title{
Will Smart Bikes Succeed as Public Transportation in the United States?
}

\author{
Paul DeMaio, City of Alexandria, Virginia \\ President of MetroBike
}

Jonathan Gifford, George Mason University Arlington Campus

\begin{abstract}
Bicycle-sharing programs have received increasing attention in recent years with initiatives to increase bike usage, better meet the demand of a more mobile public, and lessen the environmental impacts of our transportation activities. In 1996, the smart bike, or automated bike rental system, was first implemented in the United Kingdom, leading to a growing number of programs throughout Europe and Asia. However, there are presently no such programs in the United States. This article examines the potential success of smart bike programs in the United States.
\end{abstract}

\section{Introduction}

The purpose of this article is to describe briefly the history and development of bicycle-sharing, review experiences of selected smart bike, or automated bike rental programs, and develop guidelines for a successful smart bike program in the United States. In researching the article, the authors surveyed selected programs around the world, interviewed key figures in those programs, and reviewed the literature. 
The first section provides a brief history of bike-sharing programs and models. A listing of past and present smart bike programs follows it. The article concludes with a discussion of the most important characteristics that will determine the likely success of a smart bike program in the United States.

\section{Background}

Bicycles have several advantages over other modes of public transportation for short-distance urban trips because they:

- reach underserved destinations,

- require less infrastructure,

- are relatively inexpensive to purchase and maintain,

- generally do not add to vehicular congestion,

- do not create pollution in their operation, and

- provide the user with the added benefit of exercise.

In addition, bikes may increase trips on other modes of public transportation, as they expand the reach of trains and buses.

However, in comparison to other modes of transportation, bikes have their drawbacks, including:

- They can be uncomfortable in inclement weather (i.e., temperature extremes, high winds, precipitation).

- They can be used in ways unsafe to riders and pedestrians.

- They may be inaccessible to people with certain disabilities.

- They may be difficult to use in some topography.

- They require the user to have riding skills.

- They are most appropriate for shorter distances.

Two models of bike-sharing exist-one designed for community use and the other for residential use (Matsuura 2003). In the community bike-sharing model, an individual checks out a bike from one of many locations and returns it to another location. The residential bike-sharing model requires bikes to be returned at the same location from where they were checked out (usually apartment buildings). The residential model, which is used in Japan, is designed for denser cities where living and bike parking spaces are at a premium. Products such as the 
Honda Cycle Partner and Fujitec 2-Ring Park are representative of the residential bike-sharing model (Fujitec 2003; Honda 2003). However, the focus of this article is on community bike-sharing.

There have been three generations of bike-sharing systems over the past 35 years (DeMaio 2003). The first generation of bike-sharing programs began in 1968 in Amsterdam, The Netherlands. Ordinary bikes, painted white, were provided for public use. However, the bikes were stolen and the program collapsed within days (Associated Press 1998). In 1995, in Copenhagen, Denmark, a second generation of bike-sharing programs was launched with improvements. These bikes were specially manufactured and could be picked up and returned at specific locations throughout the central city with a coin deposit. However, theft of bikes in secondgeneration programs continued to be a problem, which gave rise to the smart bike or third generation bike-sharing programs.

Smartening earlier bike-sharing systems with electronically locking racks or bike locks, telecommunication systems, and smartcards or magnetic stripe cards, has allowed better tracking, as the customer's identity is known. Customers not returning a bike within the allotted time for its use, are required to pay for the replacement cost of the bike. These technological features offer great improvements over earlier systems, which had no high-tech features for checkout or return, and relied solely on customer honesty.

There are two prevalently used locking technologies in smart bike systems. In the first, bikes are checked out from an automated bike rack with the use of a smartcard or magnetic stripe card. This technology is in use by companies such as Clear Channel Adshel, JC Decaux, and Gewista. The second technology provides an automated lock on the bike itself and relies on the user to communicate via mobile or pay phone for the entry code. Deutsche Bahn uses this technology.

Smart bike fleets range in size from 50 bikes in Porsgrunn, Norway, to 1,700 bikes in Berlin, Germany. The longest running program, Vélo à la Carte, is in Rennes, France, which started in 1998. 
Figure 1. Oslo Bysykkel (SmartBike)

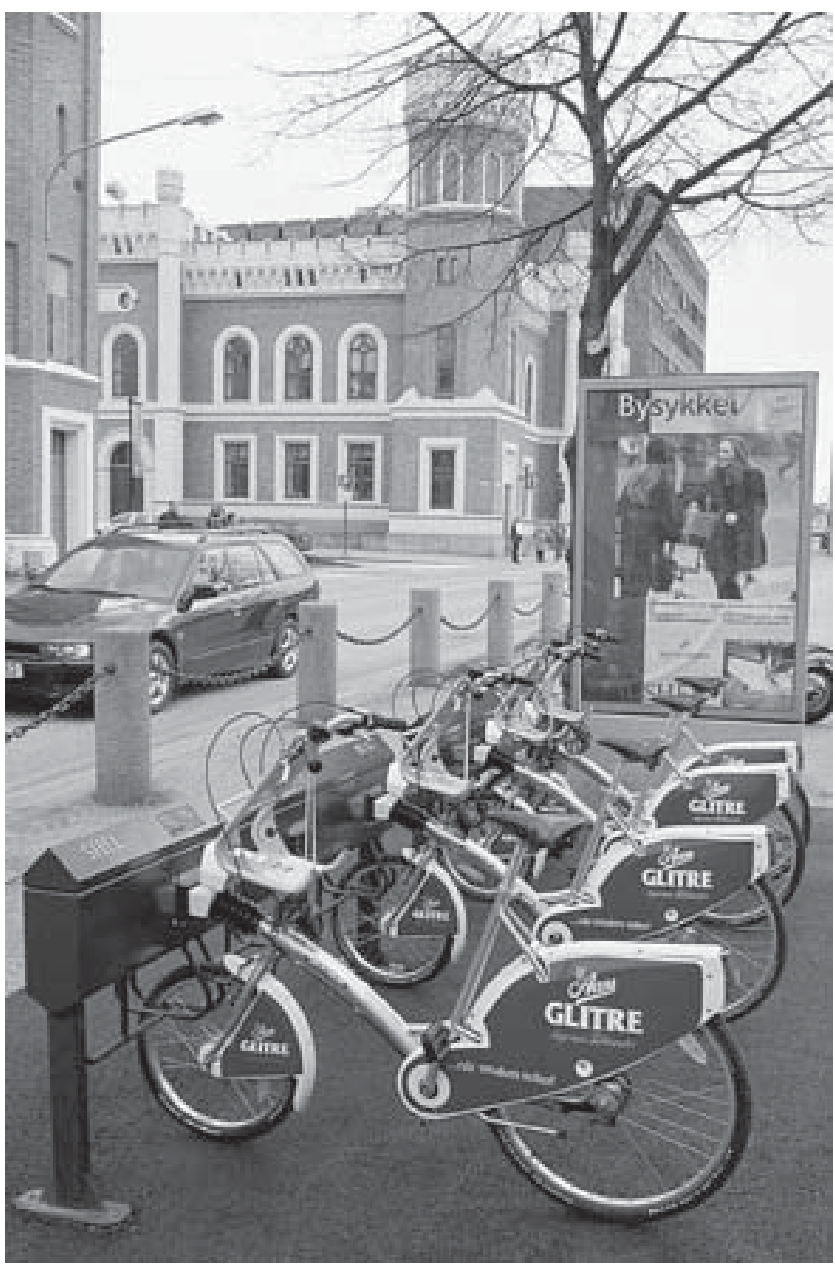

Source: Morten Kerr.

Very little research exists on bike-sharing. Literature on the similar shared-use concept for motor vehicles, called car-sharing, is extensive (see, e.g., Shaheen et al. 1998; Bonsall 2002; Cervero 2002; Litman 2003), but offers little guidance for bikesharing, as the technologies and issues are quite different. 


\section{The Smart Bike Programs}

Eleven smart bike programs currently exist worldwide, all in Europe (see Table 1). Six are provided by private companies-Clear Channel Adshel, JC Decaux, and Gewista-to local jurisdictions as part of a contract for outdoor furniture, such as bus shelters and kiosks. Three are provided by Deutsche Bahn, the German railroad company, as an extension of its passenger services. One program is offered by a quasi-governmental organization, OV-fiets, and another, Sandnes Bysykkel, is offered by the nonprofit City Bike Foundation of Sandnes.

\section{Smart Bike Suitability for the United States}

Factors critical for the success of a smart bike program in the United States include:

- customer demand,

- bike facilities and safety,

- profitability,

- theft and vandalism, and

- multimodal connectivity.

\section{Customer Demand}

The primary measurement of success of a smart bike program should be defined by demand, or ridership. Smart bikes can provide additional mobility choices for transit users and pedestrians, and thereby help retain transit riders and attract new customers. Smart bikes can assist pedestrians reach destinations that are too far or will take too long to reach by foot.

Existing smart bike programs are located in countries with relatively high percentages of individuals traveling by bike. For example, in The Netherlands, 28 percent of all trips were made by bike, and in Germany, 12 percent were made by bike in 1995 (Transportation Research Board 2001). While overall bike ridership is lower in the United States than in many European countries, more Americans are biking in recent years, and the demand for bike facilities is growing. Nationwide, bicycle modal share increased from 0.6 percent to 0.9 percent between 1977 and 1995 (Pucher et al. 1999). In the National Survey on Transportation and the Environment 2000, the Bureau of Transportation Statistics states that there are now more than 80 million U.S. residents who bicycle (U.S. Department of Transportation 2002). 
Journal of Public Transportation, Vol. 7, No. 2, 2004

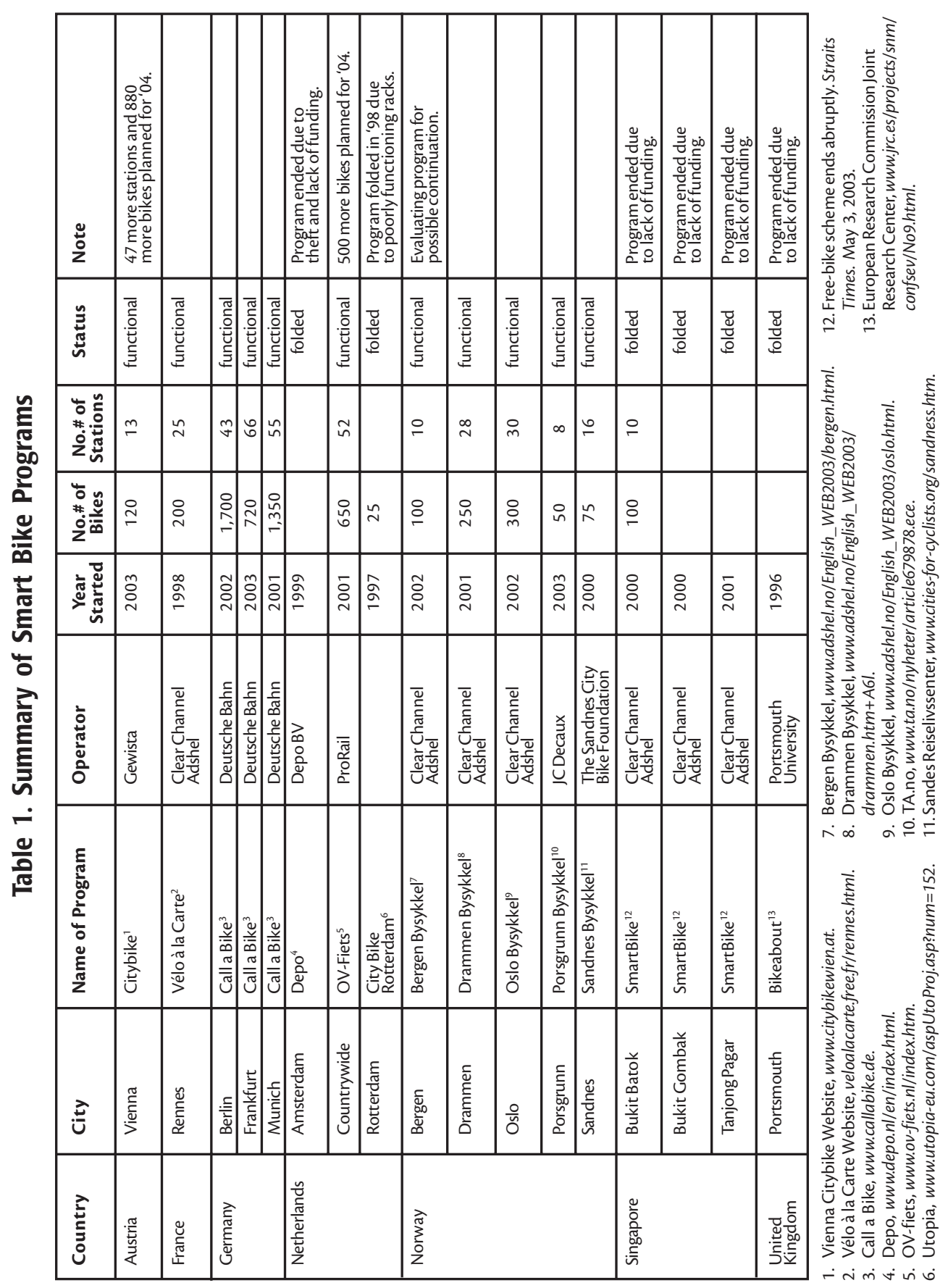


Surveys conducted by Vélo à la Carte in Rennes (France), the Danish Environmental Protection Agency, and Sandnes Bysykkel in Sandnes (Norway) suggest that potential smart bike customers are likely to be younger individuals in their twenties and thirties. In Rennes, the average age of a customer in 2003 was 31 years (Vélo à la Carte 2004). Rennes' average age is likely lowered by its being a university town. In Copenhagen, a majority of customers are between 20 and 39 years old (Danish Environmental Protection Agency 2001). In Sandnes, 45 percent of customers are between 21 and 45 years (Zanussi 2003). This is comparable with bicyclists in the United States, where 66 percent are 45 years or younger (U.S. Department of Transportation 2002). Smart bike programs in the United States would likely do well with generally younger people in their twenties and thirties.

Gender data are mixed. A majority of customers in Sandnes are male (66\%) (Zanussi 2003), while a slight majority of customers (51\%) using OV-fiets in The Netherlands are female (ProRail 2003). In the United States, 61 percent of bicyclists are male and 39 percent female (U.S. Department of Transportation 2002). Due to this, the preponderance of smart bike customers in the United States will likely be male.

While reduced traffic congestion is a noble goal, bike-sharing is likely to contribute minimally to this goal. Commuting to work represents only 9 percent of bike use in the United States (Pucher and Dijkstra 2000). Due to the low percentage of bike commuters in the United States, DiDonato et al. point out that bike-sharing will likely have little impact on traffic congestion (2002). They state that residents living downtown who want to bike will likely have their own and prefer its use. However, commuters will either drive or take transit downtown. Those arriving by car will likely not use a smart bike as a segment of their trip due to the directness car travel provides. On the other hand, commuters who take transit and must transfer or walk as part of their trip may choose to use a smart bike to save time instead of transferring or walking. Thus, of those trips made for commuting purposes, smart bikes will likely be most useful for the last leg of a trip to work or the first leg of the return home.

According to Pucher and Dijkstra, in the United States, bikes are used 82 percent of the time for social or personal business (2000). A survey conducted by OV-fiets revealed that approximately 50 percent of respondents use bike-sharing for social or personal business purposes. About 40 percent of respondents also use bikesharing for recreational purposes (ProRail 2003). These data suggest smart bikes would be well suited to use for social and personal purposes in the United States. 


\section{Bike Facilities and Safety}

Overcoming the lack of good bike facilities will be the greatest test in the application of smart bikes in the United States. Of all the countries with smart bike programs, many have a high modal split for bicycles in urban areas, including The Netherlands at 27 percent and Denmark at 20 percent. However, France has the smallest percentage at 4 percent. This is not far from the United States, which has a 1 percent modal split for bikes (Pucher and Lefevre 1996). It has yet to be determined if the U.S. bike modal split is strong enough to sustain a smart bike program.

While the United States does not have the quality and quantity of bike facilities that exist in Europe, great strides have been made over the past decade to make American cities and towns more bike friendly. As more bike facilities are created, there will be an increase in the number of bicyclists (Noland and Kunreuther 1995). As the number of bicyclists increases, so should the number of potential smart bike customers.

The notion of biking being unsafe will prevent many people from using smart bikes. There are studies dealing with the real and perceived danger of biking in the United States (Komanoff 1997; Pucher and Dijkstra 2000). John Pucher of Rutgers University states, "The overwhelming evidence is that cycling is much safer and more popular precisely in those countries where bikeways, bike lanes, special intersection modifications, and priority traffic signals are the key to their bicycling policies" (2001).

Smart bike programs must remove as much risk as possible. Customers can be provided a liability agreement, encouraged to wear a helmet, offered bike training classes, and provided a brightly colored smart bike. Also, the bikes should be maintained on a regular schedule (see the Theft and Vandalism section below).

Liability waivers for participants are common in bike-sharing programs and help to financially protect the administering organization. These agreements state the administering organization's duties regarding the maintenance of the bikes, and the customer's duties regarding safe use of the bike. Some programs, such as Germany's Call a Bike, offer the liability agreement on their website (Deutsche Bahn 2003). Others, such as the Arcata, California first-generation Library Bike, have stickers on each bike which read Ride at Your Own Risk. All Bike Laws Apply (Arcata Community Bike Program 2003). Being a litigious society, any American smart bike program would benefit from including a liability waiver. 
Requiring mandatory helmet use would likely lessen smart bike ridership as it would make usage less convenient. Customers would need to carry their own helmet during their trip to the smart bike. Also, impromptu trips via smart bike would be prevented should a customer not have a helmet with him or her. The lending of helmets by a smart bike organization or local bike shop to smart bike customers raises sanitary issues as well as liability issues due to unreported defective helmets.

To improve visibility of the customer, smart bikes in countries abroad are usually colored a bright fluorescent shade or white. Many first-generation American bikesharing programs have picked up on this safety measure. In addition, front and rear lights and reflectors also should be installed on the smart bikes. And finally, smart bikes must be maintained to ensure that each bike is in working condition.

\section{Profitability}

No smart bike program has made a profit to date. Clear Channel Adshel's smart bike systems do not charge a use fee. In addition, without advertising revenues, its smart bike programs could not operate economically (Grasso 2003). Deutsche Bahn did not disclose the profitability of Call a Bike, however, Joachim Schindler of Deutsche Bahn states, "We said in 2001 that it would take us two or three years to see a profit. We're well on our way" (Ollivier 2003).

Usage fees of the smart bike programs vary. Many have an annual membership charge of under $\$ 20$ and no usage charges as long as the bikes are returned within a specified time. The Clear Channel Adshel system follows this model. The other model has a one-time membership charge and an additional usage fee. The Call a Bike program follows this model. The usage charge for Call a Bike is 4 or 6 cents per minute depending on whether the customer has a BahnCard or ActivTarif card, which cost 60 EUR (\$68) and 20 EUR (\$23), respectively.

The authors believe that not-for-profit smart bike programs are likely to be more successful in the United States than for-profit programs. A usage fee for smart bikes in the United States would likely provide enough disincentive to limit usage. Funding revenues for the not-for-profit smart bike programs come from advertisements on the bikes or in some cases street furniture installed by the supplier. Also, local governments where the program is based may provide subsidy.

\section{Theft and Vandalism}

Theft and vandalism present serious challenges to bike-sharing programs. However, the problem of theft has been lessened due to the technological improve- 
ment of bike tracking which was added with the third generation of bike-sharing systems. Customers must provide credit card information, so if they do not return a bike, they will be charged its replacement cost.

To prevent, or at least limit, vandalism, smart bikes are designed to be utilitarian and vandal-proof. Therefore, they are usually built with puncture-proof tires, a strong frame, and an adjustable seat post. The components are designed to require the use of special tools for disassembly, thereby discouraging unauthorized removal. In addition, most of the components are of uncommon dimensions that would not be usable on other bikes. The bikes also have a unique design so as to stand out from other bikes.

Many programs have a dispatch vehicle which is used as a mobile repair station for damaged bikes. Bikes that can be fixed on the spot are, while those needing major repair can be taken to the repair center (Adshel undated).

\section{Multimodal Connectivity}

Bike-sharing programs tend to be located in downtown areas. This is primarily due to the compactness of urban development where biking is ideal. Being concentrated in an urban environment provides a greater number of potential connections than in dispersed suburban locations. Considering the average bike trip length is about two miles and 24 minutes long, short trips in urban settings are ideal for smart bikes (U.S. Department of Transportation 2001).

Bike-sharing programs also tend to colocate a portion of their bike stations at downtown transit stations in order to improve access and mobility for transit customers. As the Danish Environmental Protection Agency states, bike-sharing is well suited "to make it easier for commuters to use a bicycle on the last leg of their public transport journey" (2001). Bike stations are also located downtown at places not well served by transit. This is done to extend the reach of the transit system, thereby assisting the transit user in reaching additional locations that would previously have required a longer walk or transfer.

By providing on-demand transportation for transit customers, the modal transfer becomes a seamless exit from the transit station to the smart bike with no wait time. As the Institute of Transportation Engineers states, "Many studies have indicated that the trip time associated with waiting for or transferring to a transit vehicle is perceived to be two to three times as onerous as the actual travel time. Therefore, anything that can be done to enhance this experience will have a positive effect on attracting riders" (1997). With an on-demand bike-sharing compo- 
nent in conjunction with a transit system, the wait time between transfers will decrease, therefore customers will likely be retained and new customers attracted.

Smart bikes being truly on-demand depends on a good distribution of the bikes. When smart bike customers do not provide a satisfactory distribution of the bikes through their use, program staff can move bikes from full to empty bike stations. The dispatch vehicle is used for this task.

\section{Conclusions}

Recent strides in smart card and wireless technologies have allowed bike-sharing to evolve into the third generation of the bike-sharing concept, or smart bikes. The high-tech smart bike system, first developed in the mid-1990s, has expanded to 11 cities over the past decade, however, none so far in the United States.

Implementation of smart bike programs in the United States would provide individuals with a greater number of mobility options. Smart bikes would complement transit and walking trips to offer greater mobility to its users. Improved access to transit stations will also assist transit agencies in retaining and attracting new customers.

Biking, and smart bikes in particular, are not suitable for all people or every American city. Suitable locations include urban areas with more compact downtowns, university campuses, and dense neighborhoods with a concentration of younger people. Organizations wanting to implement smart bike programs in the United States must examine the characteristics of their city and its people to determine smart bike's appropriateness. The authors believe there are many American cities where smart bikes would likely succeed. 
Journal of Public Transportation, Vol. 7, No. 2, 2004

\section{References}

Adshel. undated. SmartBike.

Arcata Community Bike Program. 2003. http://www.arcata.com/greenbikes.

Associated Press. 1998. White bikes return to Amsterdam. http:// www.communitybike.org/cache/ap_white_bikes_return.

Bonsall, Peter. 2002. Car share and car clubs: Potential impacts. http:// www.cfit.gov.uk/mf/reports/carclubs/report/index.htm.

Cervero, Robert. 2002. City CarShare: First year travel demand impacts. http:// www.its.berkeley.edu/publications/ITSReviewonline/spring2003/trb2003/ cervero-carshare.pdf.

Danish Environmental Protection Agency. 2001. Better public transport with commuter bicycles. http://www.mst.dk/homepage/default.asp?Sub=http:// www.mst.dk/project/NyViden/1999/01160000.htm.

DeMaio, Paul. 2003. Smart bikes: Public transportation for the 21st century. Transportation Quarterly 57(1): 9-11.

Deutsche Bahn. 2003. Die Bahn und Fahrrad - Startseite Call a Bike. http:// www.callabike.de/konzern/holding/db_rent/dbag_01_Call a Bike_start.shtml.

2003. Die Tarife sowie die Allgemeinen Geschäftsbedingungen von Call a Bike. http://www.callabike.de/imperia/md/content/dbrent/12.pdf.

DiDonato, Michael, Stephen Herbert, and Disha Vachani. 2002. City-bike maintenance and availability. B.S. thesis. Worcester Polytechnic Institute. http:// www.cities-for-cyclists.org/dokumenter/igp.pdf.

Fujitec. 2003. 2-Ring Park. http://www.fujitec.co.jp/english/product/parking/2ring/ c1.htm.

Grasso, Richard. 2003. Personal communication.

Honda. 2003. Honda Cycle Partner-Electric motor-assisted bicycle sharing system. http://world.honda.com/ICVS/project/hcp/hcp.html.

Institute of Transportation Engineers. 1997. A Toolbox for alleviating traffic congestion and enhancing mobility. 156-168.

Komanoff, Charles. 1997. Restoring bicycle habitat. Bicycle Forum 45: 6-13. 
Litman, Todd. 2003. Carsharing-Vehicle rental services that substitute for private vehicle ownership. http://www.vtpi.org/tdm/tdm7.htm.

Matsuura, Masahiro. 2003. Rental Cycle System (RCS) and Community Cycle System (CCS). http://web.mit.edu/masam/www/e/bicycle/rcsccs.html.

Noland, Robert, and Howard Kunreuther. 1995. Short-run and long-run policies for increasing bicycle transportation for daily commuter trips. Transport Policy 2(1): 67-79.

Ollivier, Yann. 2003. Call a Bike-Germans pedaling a new trend. Agence France Presse.

ProRail. 2003. OV-fiets - de huurfiets in het openbaar vervoer. 11.

Pucher, John. 2001. Cycling safety on bikeways vs. roads. Transportation Quarterly 55(4): 9-11.

Pucher, John, and Lewis Dijkstra. 2000. Making walking and cycling safer: Lessons from Europe. Transportation Quarterly 54(3): 25-50.

Pucher, John, Charles Komanoff, and Paul Schimek. 1999. Bicycling Renaissance in North America: Recent trends and alternative policies to promote bicycling. Transportation Research Part A 33(7/8): 625-654.

Pucher, John, and Christian Lefevre. 1996. The urban transportation crisis in Europe and North America. London: MacMillan Press.

Shaheen, Susan, Daniel Sperling, and Conrad Wagner. 1998. Carsharing in Europe and North America: Past present and future. Transportation Quarterly 52(3): $35-52$.

Transportation Research Board. 2001. Making transit work: Insight from Western Europe, Canada, and the United States. Washington, DC: National Academy Press. 30.

Vélo à la Carte. 2003. Vélo à la Carte - SmartBike. http://veloalacarte.free.fr/ rennes.html. 2004. Statistiques de fréquentation. http://veloalacarte.free.fr/ statistiques.html.

U.S. Department of Transportation. 2001. 2001 National household travel survey. http://nhts.ornl.gov/2001/index.shtml. 
Journal of Public Transportation, Vol. 7, No. 2, 2004

2002. BTS-OmniStats 2(6, December). http://www.bts.gov/products/ omnistats/volume_2_issue_6/html/entire.html.

Zanussi, Marco. 2003. Sandnes Byke City. Paper presented at the United Nations Workshop on Sustainable and Healthy Urban Transport and Planning, November 16-18 2003, in Nocosia, Cyprus. http://unece.unog.ch/the-pep/en/ workplan/urban/documents/NorwayCaseStudy2.pdf. 


\section{About the Authors}

Paul J. DeMaio (paul@metrobike.org) is traffic calming coordinator for the City of Alexandria, Virginia, and president of MetroBike, a bike-sharing consultancy. DeMaio has a bachelor's degree in city planning from the University of Virginia, and is a master's student in the Transportation Policy, Operations, and Logistics program at George Mason University. He has published various articles on bicyclesharing programs.

Jonathan GifFoRd (jgifford@gmu.edu) is the director of the master's in Transportation Policy, Operations, and Logistics and an associate professor of public management and policy in the School of Public Policy at George Mason University in Arlington, Virginia. He has written extensively on transportation planning, policy, and institutional issues. Gifford holds a B.S. in civil engineering from Carnegie Mellon University, and a master and Ph.D. in civil engineering (transportation) from the University of California, Berkeley. 